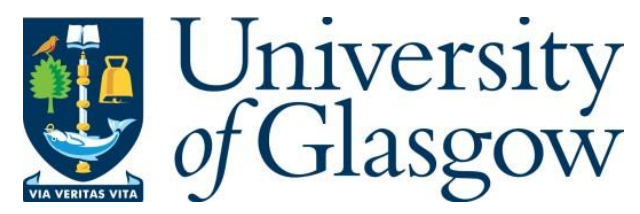

Sun, J., Abdulghani, A. M., Imran, M. A. and Abbasi, Q. H. (2020) IoT Enabled Smart Fertilization and Irrigation Aid for Agricultural Purposes. In: 2020 International Conference on Computing, Networks and Internet of Things (CNIOT 2020), Sanya, China, 24-26 Apr 2020, pp. 71-75. ISBN 9781450377713.

There may be differences between this version and the published version. You are advised to consult the publisher's version if you wish to cite from it.

(C) Association for Computing Machinery 2020. This is the author's version of the work. It is posted here for your personal use. Not for redistribution. The definitive Version of Record was published in Proceedings of the 2020 International Conference on Computing, Networks and Internet of Things (CNIOT 2020), Sanya, China, 24-26 Apr 2020, pp. 71-75. ISBN 9781450377713.

http://dx.doi.org/10.1145/3398329.3398339.

http://eprints.gla.ac.uk/214990/

Deposited on: 29 April 2020

Enlighten - Research publications by members of the University of Glasgow http://eprints.gla.ac.uk 


\section{IoT Enabled Smart Fertilization and Irrigation Aid for Agricultural Purposes}

\author{
Jieying Sun \\ James Watt School of Engineering \\ University of Glasgow \\ Glasgow, United Kingdom \\ 2357559S@student.gla.ac.uk \\ sunjieying30@126.com \\ Muhammad A. Imran \\ James Watt School of Engineering \\ University of Glasgow \\ Glasgow, United Kingdom \\ Muhammad.Imran@glasgow.ac.uk
}

\author{
Amir M. Abdulghani \\ Oman \& James Watt School of Engineering \\ Sultan Qaboos University, University of Glasgow \\ Glasgow, United Kingdom \\ amirmohamed.abdulghani@glasgow.ac.uk
}

\begin{abstract}
Soil is of great importance to agriculture, specially the moisture and nutrients in the soil are the essential ingredients for growing plants and crops. Therefore, benefits and importance of a soil moisture and nutrient monitoring system in modern agriculture and gardening is undeniable. It can also be an interesting feature of an intelligent home or smart agriculture system using the internet of things (IoT) technology. This paper presents an IoT application in Arduino platform aiming to monitor the change in soil moisture and Nitrogen (N), Phosphorus (P), Potassium (K) (NPK) value for an indoor plant using moisture sensors and optical transducers. Other functionalities and important features of this prototype include online data display infographic as user feedback, level-based nutrient classification for enabling proper type of fertilizer selection, hardware and e-mail notification of moisture and nutrients' easily accessible and user-friendly smartphone app.
\end{abstract}

\section{CCS CONCEPTS}

-Hardware Communication hardware, interfaces and storage $\sim$ Wireless devices $\bullet$ Hardware $\sim$ Communication hardware, interfaces and storage $\sim$ Sensor applications and deployments $\cdot$ Hardware Communication hardware, interfaces and storage - Sensor devices and platforms • Computing methodologies $\sim$ Artificial intelligence $\sim$ Computer vision -Networks $\sim$ Network types $\sim$ Wireless access networks
Permission to make digital or hard copies of part or all of this work for personal or classroom use is granted without fee provided that copies are not made or distributed for profit or commercial advantage and that copies bear this notice and the full citation on the first page. Copyrights for third-party components of this work must be honored. For all other uses, contact the owner/author(s). CNIOT 2020, April, 2020, Sanya, China

(C) 2020 Copyright held by the owner/author(s).

ACM ISBN 978-1-4503-7771-3

\section{KEYWORDS}

Internet of Things, Smart agriculture, Sensors, Arduino, NPK value measurement

\section{ACM Reference format:}

Jieying Sun, Amir M. Abdulghani, Muhammad A. Imran and Qammer H. Abbasi. 2020. IoT Enabled Smart Fertilization and Irrigation Aid for Agricultural Purposes. In Proceedings of 2020 International Conference on Computing, Networks and Internet of Things (CNIOT 2020), April 2426, 2020, Sanya, China. ACM, New York, NY, USA, 5 pages.

\section{Introduction}

In traditional agriculture related practices, three basic elements of importance for the production of crops are soil, climate and topography. Roots absorb maximum water and nutrients from soil which support the biochemical reaction and nutrientsaccumulation inside the plant. Different climates stand for different temperature, illumination, precipitation and monsoon. The elevation and gradient in each topographical region allow soil gathering to grow plants.

Comparing to other artificial factors such as mutation breeding, greenhouse construction and crop rotations, maintaining soil properties is the most practical method to improve crop production. Farmers change soil environment by applying extra water and nutrients, known as irrigation and fertilization. Irrigation process provides adequate water for crop growth and balancing the inner water cycle. Fertilization process adds different ratio of NPK in the soil, representing Nitrogen $(\mathrm{N})$, Phosphorus (P), Potassium (K). It adjusts the $\mathrm{PH}$ value in soil environment and promotes the growth of plants differently, such as $\mathrm{N}$ for leaves and vegetation, $\mathrm{P}$ for roots, $\mathrm{K}$ for flower, fruit and 
plant cell. Those two agricultural practices could promote the taste, size, quality and quantity of harvest, if the farmer follows the correct experiences in cultivation.

However, in modern agriculture, manual irrigation and fertilization cannot catch up with the fast-paced crop production required by the ever-increasing global population. The automated systems for irrigation and fertilization are already being deployed and being used very effectively, but decisions related as to when to irrigate and fertilize the plant still mainly depends and requires some level of human intervention. The machines are not intelligent enough as humans to estimate the uncertain period for agricultural practice. This provides a challenge and opportunity to step in the direction of decision automation in agricultural technology and practices. The waste in irrigation water for agricultural uses is also one of the main public concerns as consumers are more interested to buy products with ideally no or at least less remaining harmful artificial fertilizer residues. Therefore, farmers should find the best amount of fertilizer and water for each crop to reduce waste, establish brand with good reputation, safe and healthy products and earn more profit.

This sets the stage for an Internet of Things application that has been developed and presented as part of this work. The system presented here includes both hardware and software to assist modern farmers and gardeners. It detects the moisture and NPK value inside the soil, which stands for irrigation and fertilization. After performing data analysis, farmer is informed (i) when to start irrigation and fertilization, (ii) the proper amount of fertilizer and water are needed to reduce waste, (iii) and choose the proper type of fertilizer that suits the plants most with a user-friendly surface. This prototype can also be used in a high-tech Smart home environment for watering plants and intelligently fertilizing them.

\section{Methods}

In industrial agriculture field, there are hundreds of IoT irrigation applications which monitor the moisture inside the soil and linked to irrigation spray or drones. But there are seldom applications for fertilizer due to the black hole in NPK sensor. Thanks to a study in Universiti Teknologi Mara which detects NPK value by using optical transducer in 2017, NPK is allowed to be detected now by using Arduino microcontroller and sensors.

The previous study found that Nitrogen, Phosphorus, Potassium absorb light in different wavelength and the value of $\mathrm{N}, \mathrm{P}, \mathrm{K}$ could be measured by the absorption light from each nutrient. So, three LEDs in different wavelength band that suits the nutrient are set to be light source. Photodiodes work as sensors to detect the remaining light after passing through soil sample. Therefore, the level of NPK in the soil can be calculated by absorption. Table I lists optical characteristics of NPK soil absorption and the corresponding characteristic of the chosen LEDs.

\begin{tabular}{|l|l|l|l|}
\hline Nutrient & $\begin{array}{l}\text { Absorption } \\
\text { wavelength(nm) }\end{array}$ & LED & $\begin{array}{l}\text { LED } \\
\text { wavelength(nm) }\end{array}$ \\
\hline Nitrogen $(\mathrm{N})$ & $438-490$ & Blue LED & 470 \\
\hline Phosphorus (P) & $528-579$ & Green LED & 568 \\
\hline Potassium (K) & $605-650$ & Red LED & 624 \\
\hline \multicolumn{4}{|l}{ Photodiode testing range: $400 \mathrm{~nm}$ to $1100 \mathrm{~nm}$} \\
\hline
\end{tabular}

Table I: Optical characteristics of NPK soils and led

Absorbance (A) according to Beer's Law has the following equation:

$$
A=-\log _{10} \frac{I_{I}}{I_{O}}
$$

Absorbance (A) according to Beer's Law has the following equation: Where $\mathrm{I}_{\mathrm{I}}$ is the transmitted light intensity and $\mathrm{I}_{\mathrm{o}}$ is incident light intensity. The value of the intensity level can be evaluated by the voltage converted by photodiode. So, the absorption level which represent the NPK value was measured. Then after comparing with threshold values set in Arduino microcontroller, the NPK value is divided in two five levels. These threshold values were determined based on the absorption measurement of sample soil with NPK 202020.

Overall, in order to demonstrate the state aim, the project connect Grove Moisture Sensor, specific LED \& photodiode with Arduino hardware. It will develop Internet of Thing program to transmit measurements to gateway at proper rate, and algorithm will use to classify data into different level, demonstrate the value in figure, convert the received value into standard unit, given out the ratio between the NPK absorbed by plants, calculate the proper amount of water and nutrient to reduce waste.

\section{Prototype Design}

The prototype is based on IoT technology assisting in agricultural fertilization and irrigation. It measures the moisture and nutrients from plant soil, uploads and stores data online, shows them on user feedback dashboard and send notification via peripherals or e-mail.

\subsection{Block Diagram \& Hardware Schematic}

This prototype is a combination of hardware and software. The hardware is consisting of Power source, Moisture Sensor, NPK sensor, display peripheral (in this case we use LED display module) and the Arduino Uno microcontroller. After receiving the value from the sensors, firstly, the Arduino is connected to The Things Network gateway through OTAA mode and access to TTN online console. Then data is sent and stored in a second platform Ubidots via HTTP. The communication between The Things Network and Ubidots is bidirectional, so a downlink message will send back through TTN to control hardware if the data value triggers an event on Ubidots. Also, other online events such as e-mail or text notification can be triggered by eligible data on the same platform. Figure 1 shows the block diagram of this prototype and Figure 2 shows the hardware schematic. 
IoT Enabled Smart Fertilization and Irrigation Aid for Agricultural Purposes

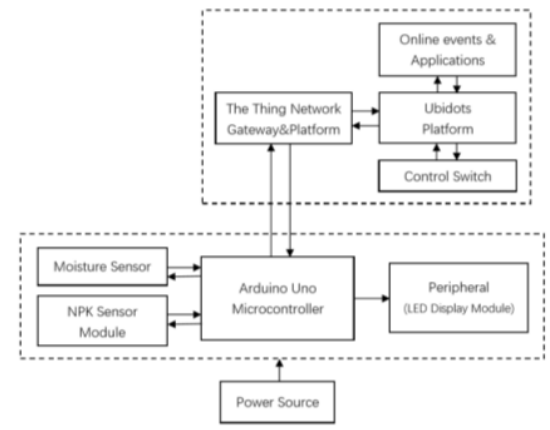

Figure 1: Block Diagram

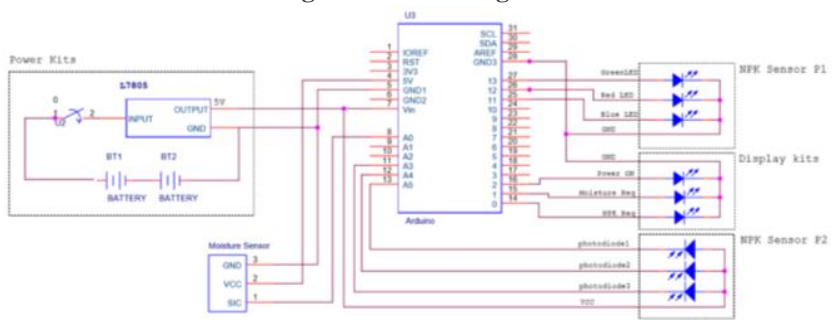

Figure 2: Hardware Schematic

\subsection{System flowchart for the developed system}

Figure 3 shows the system flowchart for the software system of this prototype. To begin with, the Arduino is initialized and a variable controlled by online switch is checked endlessly, which sends downlink command to trigger the measurement. Then the moisture and NPK value read from the sensors will be sent to TTN and Ubidots Platform. After doing further processing, data will show in user feedback dashboard. If data triggers an event, relative downlink will be sent back to Arduino to control the display peripheral (LED in this case), and e-mail notification will be sent at the same time too.

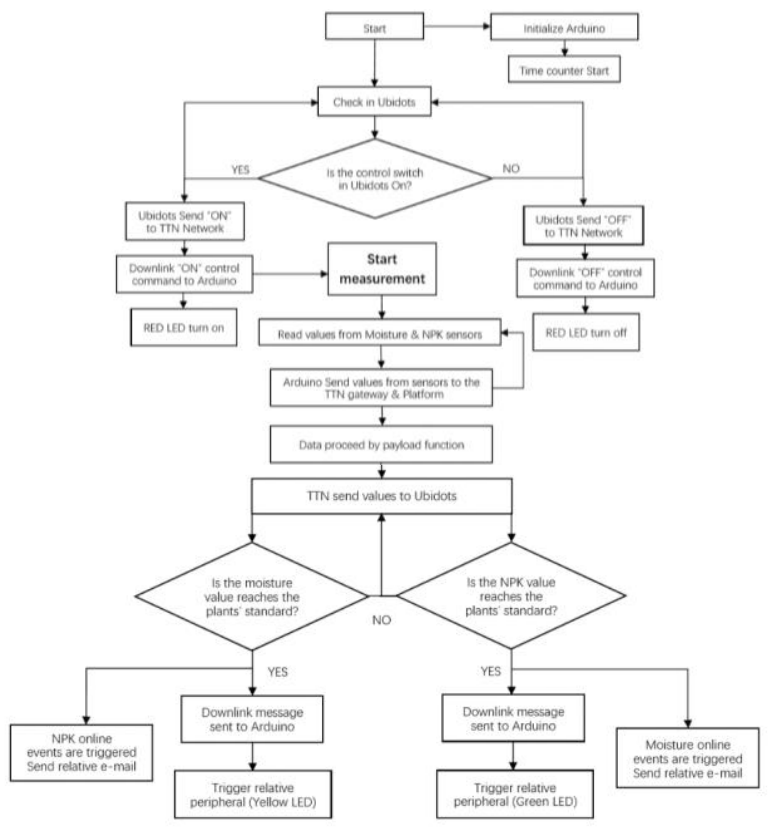

Figure 3: System flowchart for the developed system
CNIOT 2020, April, 2020, Sanya, China

\subsection{Prototype Demonstration}

Figure 4 shows the prototype of hardware, including Power supply unit with display kits, Moisture Sensor, NPK sensor $(\mathrm{P} 1+\mathrm{P} 2)$ and the Arduino Uno microcontroller. Figure 5 demonstrates how this IoT application work with real plants.

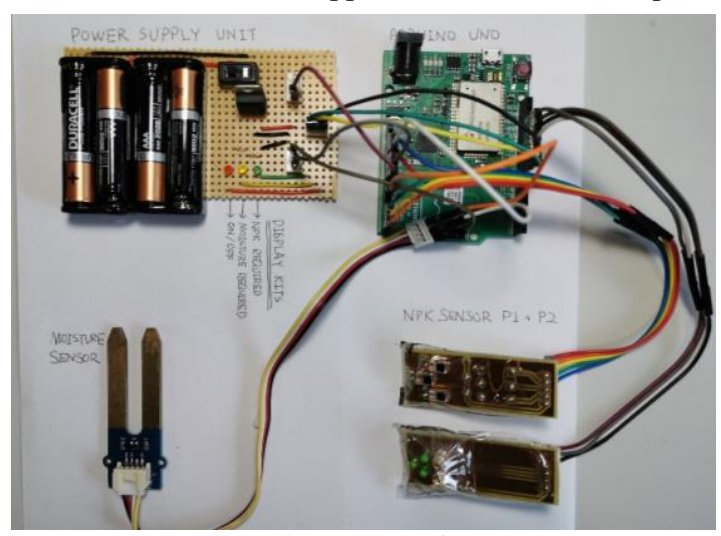

Figure 4: Prototype of hardware

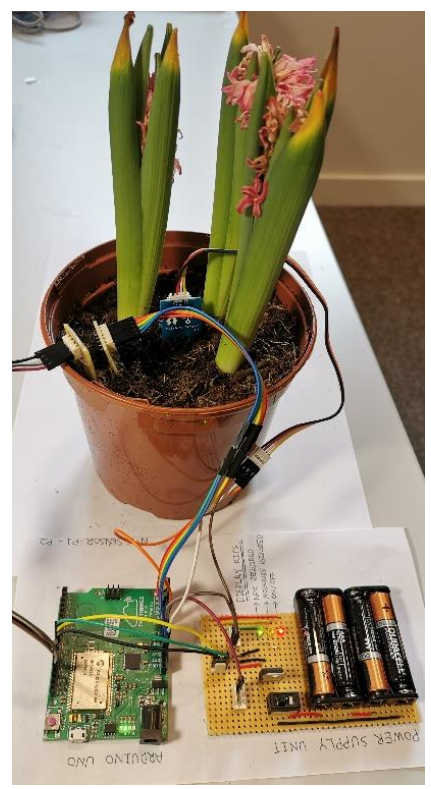

Figure 5: Demonstration

When the prototype hardware and programmed software are working together on either TTN and Ubidots platform, the following functions can be achieved:

- Control the application via a digital switch online using smartphone or laptop

- Measure Moisture and NPK value from the plant soil and store the data online

- Divide the NPK value into five different levels on Ubidots dashboard

- Show real-time values of Moisture and NPK in Ubidots dashboard and plot the diagram 
- Send an email when Moisture and NPK value is under certain level to notice the user that watering or fertilizing is required by plants. The required volume of water and proper type of fertilizer are also projected to be shown on this email.

- Trigger a relative event in Arduino when Moisture and NPK value is under certain level. This is shown by lighten different display LED in this case. (Red LED represents whether the prototype is ON/OFF, Yellow LED represents the plant is requiring moisture, Green LED represents the plant is requiring fertilizer.)

- All the values, diagrams and switch which are shown on Ubidots dashboard can be accessed by an official APP on smartphone or Tablet device.

\section{Results \& Discussion}

The prototype collects the moisture value, NPK value from a sample plant in dark environment in two days. Calculate the NPK absorption in the soil and divide them into level.

\subsection{Data Analyzation}

This data is shown in Table II, which is copied from Ubidots.

\begin{tabular}{|c|c|c|c|c|c|c|c|}
\hline & Moisture & $\mathrm{N}$ & $\mathrm{P}$ & $\mathrm{K}$ & $\mathrm{N}_{\text {Atwappitas }}$ & $\mathrm{P}_{\text {Aturagesian }}$ & $\mathrm{K}_{\text {Atsaprite }}$ \\
\hline $2020-03-3020: 48: 48+01: 00$ & 593 & 90 & 113 & 78 & 0.00 & -0.01 & 0.01 \\
\hline $2020-03-3018: 47: 13+01: 00$ & 593 & 90 & 113 & 78 & 0.00 & -0.01 & 0.01 \\
\hline $2020-03-30$ 18:47:01+01:00 & 597 & 88 & 113 & 78 & 0.01 & -0.01 & 0.01 \\
\hline $2020-03-3016: 47: 10+01: 00$ & 597 & 88 & 113 & 78 & 0.01 & -0.01 & 0.01 \\
\hline $2020-03-3014: 57: 30+01: 00$ & 603 & 88 & 113 & 75 & 0.01 & -0.01 & 0.03 \\
\hline $2020-03-3010: 51: 09+01: 00$ & 607 & 88 & 110 & 75 & 0.01 & 0.00 & 0.03 \\
\hline $2020-03-3008: 46: 20+01: 00$ & 612 & 87 & 110 & 75 & 0.01 & 0.00 & 0.03 \\
\hline $2020-03-30$ 04:41:44 +01:00 & 621 & 87 & 109 & 73 & 0.01 & 0.00 & 0.04 \\
\hline $2020-03-3002: 47: 05+01: 00$ & 624 & 85 & 109 & 73 & 0.02 & 0.00 & 0.04 \\
\hline $2020-03-3000: 47: 09+01: 00$ & 628 & 85 & 109 & 70 & 0.02 & 0.00 & 0.06 \\
\hline $2020-03-2922: 46: 49+01: 00$ & 633 & 85 & 105 & 70 & 0.02 & 0.02 & 0.06 \\
\hline $2020-03-2920: 46: 36+01: 00$ & 640 & 83 & 105 & 70 & 0.04 & 0.02 & 0.06 \\
\hline $2020-03-29$ 18:47:08 +01:00 & 643 & 83 & 105 & 69 & 0.04 & 0.02 & 0.06 \\
\hline $2020-03-29$ 16:46:23 +01:00 & 249 & 83 & 102 & 69 & 0.04 & 0.03 & 0.06 \\
\hline $2020-03-29$ 14:46:06 +01:00 & 259 & 81 & 102 & 69 & 0.05 & 0.03 & 0.06 \\
\hline $2020-03-2912: 47: 58+01: 00$ & 265 & 81 & 102 & 65 & 0.05 & 0.03 & 0.09 \\
\hline $2020-03-29$ 10:43:25 +01:00 & 280 & 81 & 102 & 65 & 0.05 & 0.03 & 0.09 \\
\hline $2020-03-29$ 08:43:18 +01:00 & 293 & 80 & 102 & 65 & 0.05 & 0.03 & 0.09 \\
\hline $2020-03-29$ 06:43:04 +01:00 & 304 & 80 & 101 & 62 & 0.05 & 0.04 & 0.11 \\
\hline $2020-03-29$ 04:42:14 +01:00 & 310 & 80 & 101 & 62 & 0.05 & 0.04 & 0.11 \\
\hline $2020-03-29$ 02:41:56 +01:00 & 327 & 79 & 101 & 62 & 0.06 & 0.04 & 0.11 \\
\hline $2020-03-29$ 00:41:14+00:00 & 342 & 79 & 101 & 60 & 0.06 & 0.04 & 0.12 \\
\hline $2020-03-2822: 40: 02+00: 00$ & 369 & 79 & 99 & 60 & 0.06 & 0.05 & 0.12 \\
\hline
\end{tabular}

Table II : Data from Ubidots

For data specification, the moisture sensor collects sample data from the plant in every two hours (12 times/day), and the NPK sensor collect sample NPK value from the plant in every six hours (4 times/day), according to the changing rate of moisture and nutrients in agricultural testing. In this table, all of the data is collected is in analog signal for accuracy, which represent the voltage on Arduino pins using ADC method, so there are no unit for them.

As $V_{\text {analogue }}=I_{I} \times R_{\text {pin }}$, according to equation (1), the light absorption can be calculated by

$$
A=-\log _{10} \frac{V_{\text {analogue }}}{V_{\text {th }}}
$$

Where the threshold value for Nitrogen $(\mathrm{N})$ is 91, Phosphorus $(\mathrm{P})$ is 110 , and Potassium $(\mathrm{K})$ is 78 . These values are measuring with the plain soil, which is the sample soil dipped in water for days, filtered the nutrients and dried under the sun.

According to the fact measuring soil with NPK 2020 20, there is $\mathrm{A}_{\mathrm{N}}=0.12, \mathrm{~A}_{\mathrm{P}}=0.10, \mathrm{~A}_{\mathrm{K}}=0.11$. So, for dividing the absorption value in to different level, we use table III:

\begin{tabular}{|c|c|}
\hline Level 1: & $\mathrm{A}<0$ \\
\hline Level 2: & $0 \leqslant \mathrm{~A}<0.03$ \\
\hline Level 3: & $0.03 \leqslant \mathrm{~A}<0.06$ \\
\hline Level 4: & $0.06 \leqslant \mathrm{~A}<0.10$ \\
\hline Level 5: & $0.10 \leqslant \mathrm{~A}$ \\
\hline
\end{tabular}

\subsection{Dashboard Output}

Figure 6 shows the final output in Ubidots user feedback dashboard. It represents the data in Table II, using numbers, line chart, gauge and tank diagrams. And the email notification including suggested water volume and fertilizer type for irrigation and fertilization is shown in Figure 7.

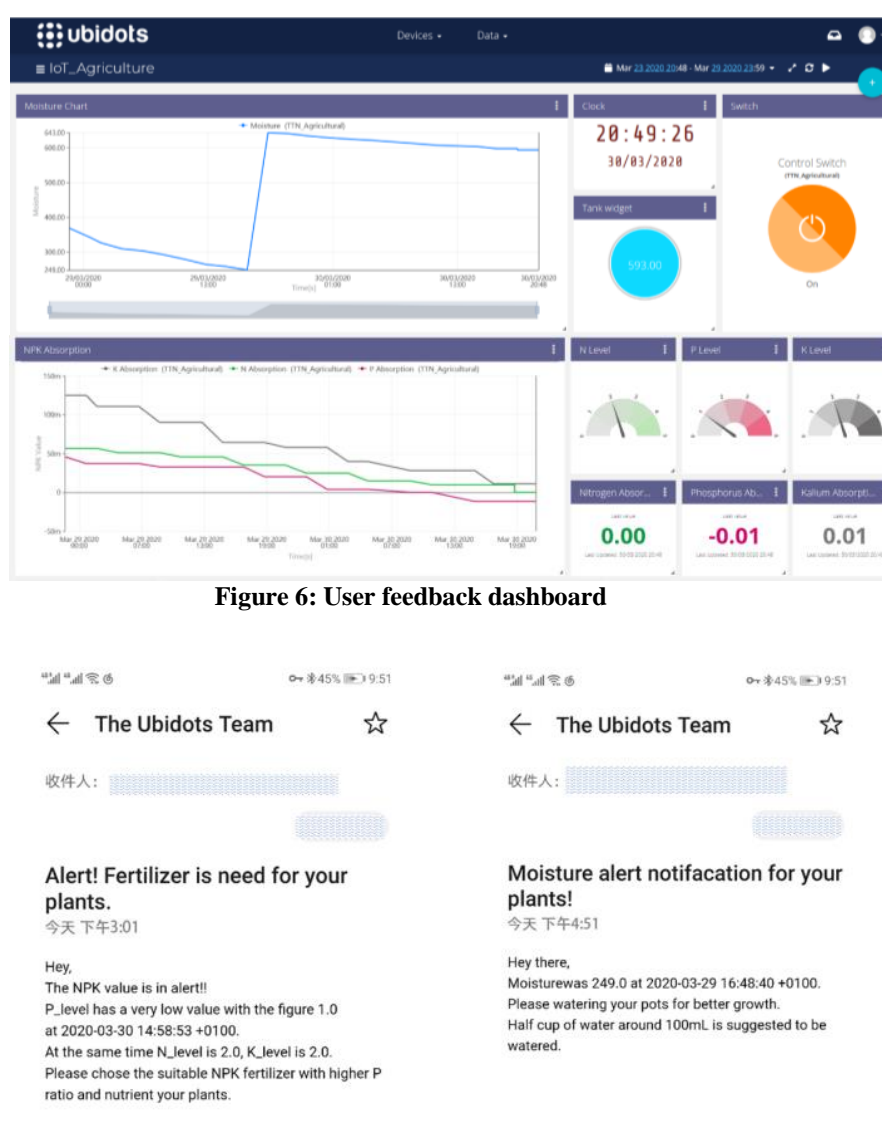

Figure 7: E-mail feedback

From Figure $6 \& 7$, it is clear that the plant has being watered after an email requiring for water is receive from the terminal at 202003-29 16:48, then the moisture value rise back to six hundred. 
Also, at the end of these two days, another email is received for fertilizing as the Phosphorus (P) element in soil falls to level 1 when Nitrogen $(\mathrm{N})$ and Potassium $(\mathrm{K})$ levels are 2. So, fertilizer with higher ratio of $\mathrm{P}$ should be selected for next fertilizing.

\subsection{Limitation}

For data specification, the time delay caused by hardware devices is normally $10 \mathrm{~ns}-20 \mathrm{~ns}$. The delay of transmitting data to The Things Network console is around 2.5 seconds. The time lag for data transmitted from The Things Network to Ubidots dashboard is around 2-3 seconds which also depends on the network speed. Therefore, the total time delay for this application to have a user feedback is 5 seconds, which affects nothing to agriculture IoT.

The testing of NPK value is strongly affected by the indoor light, so plant in this example do whole test in dark environment. And the NPK result seems not accurate enough due to the influence of particle inside the soil. Also, this IoT prototype only suits for general plants. The standard value of some specific plants is not included in the database like the threshold moisture value for cactus.

\section{Future Development}

There are some points required further development in this prototype. For example, in the hardware, NPK sensor with better function needs to be considered. PH value testing module in soil needs to be developed using Arduino platform, that can be installed in the improved version of this IoT system. Other peripheral equipment to automatically irrigate or fertilize the plants is needed, making the agriculture helper smarter and more interactive.

In the software, an algorithm aiming to give detailed selection of fertilizer type should be done instead of just giving out the fuzzy range. Apart from that, although there is a smartphone app for Ubidots and this IoT prototype can use this platform, a customized app should be designed for better user experience, aesthetics, customization and marketing purposes.

\section{Conclusion}

This Internet of things prototype measures moisture and NPK value from the plant soil, classify the NPK value into different level and display proper data via diagram on user's feedback dashboard. Moreover, users can access to this IoT application feedback using a smartphone App provided by Ubidots, and relative peripheral or e-mail notification will response to moisture and NPK value in this platform too. This prototype can also operate with other systems, such as automatic spraying mechanism, drones etc. It gives suggestions to farmers such as when to irrigate and fertilize, the amount of water and fertilizer should be used each time, and which type of fertilizer with NPK ratio suits the plants most. This prototype also contributes to smart home as it is linked to smartphone and handheld device. It can inform the house owners to water or fertilize the plant on time by using email alerts and online feedback dashboard.

\section{ACKNOWLEDGMENTS}

Authors would like to acknowledge Glasgow College, UESTC and Sultan Qaboos University (Government of the Sultanate of Oman) for supporting Dr. Amir M. Abdulghani.

\section{REFERENCES}

[1] A. Nayyar and E.V. Puri, "Smart Farming: IoT Based Smart Sensors AgricultureStick for Live Temprature and Moisture Monitoring using Arduino, Cloud Computing \& Solar Technology" [online], Available: www.researchgate.net

[2] C.S. Nandyala and H. Kim, "Green IoT Agriculture and Healthcare Application (GAHA)," in International Journal of Smart Home[online], vol. 10, no. 4, pp. 289-300, 2016, Available: http://dx.doi.org/10.14257/ijsh.2016.10.4.26

[3] M. Kižlo and A. Kanbergs, "The Causes of the Parameters Changes of Soil Resistivity," in Scientific Proceedings of Riga Technical University, The 50 ${ }^{\text {th }}$ international scientific conference, Power and Electrical Engineering. pp. 4344, 2009.

[4] R.Sindhuja and B.Krithiga, "Soil Nutrient Identification Using Arduino," in Asian Journal of Applied Science and Technology (AJAST), vol.1, issue 4, pp. 40,2017

[5] C.Broertjes and A.M.V. Harten, Application of Mutation Breeding Methods in the Improvement of Vegetatively Propagated Crops, Amsterdam Netherlands, 1978, pp. 1-5

[6] N. Castilla and E. Baeza, "Greenhouse site selection" in Good Agricultural Practices for greenhouse vegetable crops[online]. pp.21-23, Available: www.fao.org/publications

[7] M. Farooq, A.A. Bajwa, S.A. Cheema and Z.A. Cheema, "Application of Allelopathy in Crop Production," in International Journal of Agriculture \& Biology, vol.15, no.6, 2013

[8] N. Singh and A. Shaligram, "D. NPK Measurement in Soil and Automatic Soil Fertilizer Dispensing Robot,” International Journal of Engineering Research \& Technology, vol. 3, no. 7, pp. 635-637, 2014

[9] M. Masrie, M. S. A. Rosman, R. Sam and Z. Janin, "Detection of Nitrogen, Phosphorus, and Potassium (NPK) nutrients of soil using Optical Transducer, "in Proc. of the 4th IEEE International Conference on Smart Instrumentation, Measurement and Applications (ICSIMA), 2017

[10] D. A. Skoog, D. M. West, F. J. Holler, and S. R. Crouch, Fundamentals of Analytical Chemistry. Cengage Learning, 2013. 